\title{
Site Specific Inelasticity of Arterial Tissue
}

\author{
Eoghan Maher ${ }^{1}$, Michael Early ${ }^{1}$, Arthur Creane ${ }^{2}$, Caitríona Lally ${ }^{1,2}$, Daniel J. Kelly ${ }^{1}$
}

1. Trinity Centre for Bioengineering, School of Engineering, Trinity College, Dublin, Ireland.

2. School of Mechanical and Manufacturing Engineering, Dublin City University, Dublin, Ireland.

Corresponding author:

Dr. Daniel Kelly,

Trinity Centre for Bioengineering,

School of Engineering,

Trinity College,

Dublin,

Ireland.

$\mathrm{Ph}+353-1-8963947 \quad$ Fax $+353-1-6795554$

E-mail: kellyd9@tcd.ie

Keywords: Arterial Tissue, Inelasticity, Mechanical Properties, Angioplasty, Stent, Coronary

Word count: 3640 (Excl abstract and references) 


\section{Abstract}

2 Understanding the mechanical behaviour of arterial tissue is vital to the development and

3 analysis of medical devices targeting diseased vessels. During angioplasty and stenting, stress

4 softening and permanent deformation of the vessel wall occur during implantation of the

5 device, however little data exists on the inelastic behaviour of cardiovascular tissue and how

6 this varies through the arterial tree. The aim of this study was to characterise the magnitude

7 of stress softening and inelastic deformations due to loading throughout the arterial tree and

8 to investigate the anisotropic inelastic behaviour of the tissue. Cyclic compression tests were

9 used to investigate the differences in inelastic behaviour for carotid, aorta, femoral and coronary arteries harvested from 3-4 month old female pigs, while the anisotropic behaviour of aortic and carotid tissue was determined using cyclic tensile tests in the longitudinal and circumferential directions. The differences in inelastic behaviour were correlated to the ratio of collagen to elastin content of the arteries. It was found that larger inelastic deformations occurred in muscular arteries (coronary), which had a higher collagen to elastin ratio than elastic arteries (aorta), where the smallest inelastic deformations were observed. Lower magnitude inelastic deformations were observed in the circumferential tensile direction than in the longitudinal tensile direction or due to radial compression. This may be as a result of non-fibrous matrix or smooth muscle in the artery becoming more easily damaged than the collagen fibers during loading. Stress softening was also found to be dependent on artery type. In the future, computational models should consider such site dependant, anisotropic inelastic behaviour in order to better predict the outcomes of interventional procedures such as angioplasty and stenting. 
2 Stenting and balloon angioplasty are common procedures to treat atherosclerotic arteries

3 through mechanical loading of the lesion. In order to be able to predict the outcome of these 4 procedures, and to properly analyse new cardiovascular medical device designs, a thorough

5 understanding of both healthy and diseased arterial tissue mechanical behaviour is necessary.

6 Arteries are multi-layered vessels with each layer containing different proportions of the main

7 structural components of arteries, namely collagen, elastin fibrils and smooth muscle cells.

8 Arteries can be divided into two broad categories: elastic and muscular arteries, with the 9 diameter, layer thicknesses and layer compositions depending on the artery type (Martini, 2006). The mechanical properties of arteries are largely determined by the relative amounts of collagen, elastin and smooth muscle it contains, and the structural organization of these components. The elastin and collagen components are the main determinants of the elastic behaviour of arteries, with the lower stiffness elastin having prominence at low strains or pressures and the higher stiffness collagen fibers determining the large strain behaviour (Roach and Burton, 1957; Salvucci et al., 2009). The vascular smooth muscle content of the arteries is closely related to the viscoelastic properties of the tissue such as stress relaxation (Salvucci et al., 2009). As the proportional content of these components in arteries determines their mechanical behaviour it is clear that arterial mechanical properties will vary throughout the arterial tree.

A number of studies have investigated the elastic behaviour of arterial tissue (Garcia et al., 2011; Lally et al., 2004; Schulze-Bauer et al., 2003; Sommer et al., 2010) and its failure characteristics (Holzapfel et al., 2004; Stemper et al., 2007; Teng et al., 2009; Walraevens et al., 2008). It has been reported that arterial tissue displays anisotropic characteristics (Garcia et al., 2011; Holzapfel et al., 2005; Holzapfel et al., 2004) which has been attributed to the orientation of the collagen fibers (Holzapfel, 2006) and to the 
1 anisotropy of the elastin network (Zou and Zhang, 2009). Viscoelastic behaviour such as

2 stress relaxation (Silver et al., 2003; Yang et al., 2011) and strain rate dependency of the stress-strain response (Yang et al., 2011) has also been observed. While there are studies in the literature that compare the elastic (Patel and Janicki, 1970; Salvucci et al., 2009; Silver et al., 2003) or viscoelastic (Salvucci et al., 2009; Silver et al., 2003) behaviour of different vessels, to the authors' knowledge little data exists characterising or comparing stress softening and the inelastic deformations that occur on unloading due to damage induced within the tissue and how this behaviour will vary throughout the arterial tree. As the ultimate goal of clinical procedures such as stenting and angioplasty is to maximise the post-procedure lumen gain, further work is required to characterise inelastic deformations due to the damage that results from over-stretching the tissue beyond the physiological domain. commonly used in studies to mechanically characterise arterial tissue (Dixon et al., 2003; Lally et al., 2004; Pandit et al., 2005; Silver et al., 2003). This approach has been justified due to the similarities between the human and porcine cardiovascular systems and the fact that porcine models are commonly used in the pre-clinical evaluation of medical devices. The objective of this study was to characterise the variation in the inelasticity of arterial tissue throughout the porcine arterial tree. In particular we sought to determine the magnitude of stress softening and residual inelastic deformations that result on unloading of arterial tissue from non-physiological strains. Residual strain is the term used in this study to describe the remnant strain in the tissue on unloading from a supra-physiological load. It is defined here as the strain (characterised from the original sample length) in the sample at which the specimen becomes stressed on reloading the sample; i.e. it is the strain at which the sample will start to take load. Residual strain has been referred to as remnant strain (Balzani et al., 2011) or permanent set (Pena, 2011) in other studies of soft tissue behaviour. Stress-softening 
1 is an inelastic phenomenon similar to the Mullins effect in polymers and rubbers. It results in

2 a softening of the stress-strain response in the tissue between the first loading cycle and

3 subsequent unloading and reloading cycles. To further characterise this response, the

4 anisotropic inelastic behaviour was also investigated. To this end, tissue from porcine

5 thoracic aorta, proximal common carotid, femoral and right coronary arteries were subjected

6 to radial compression, while aortic and carotid tissue was further tested in circumferential and

7 longitudinal tension to characterise the anisotropy of the inelastic response.

9 2. Materials and Methods

10 Arterial tissue was harvested from 3-4 month old female pigs using a scalpel within one hour 11 of the pig being put down. Fat and connective tissue were trimmed from the arteries, which 12 were then stored in $0.9 \%$ saline solution at $4{ }^{\circ} \mathrm{C}$. Four artery types were harvested; common carotid arteries, femoral arteries, right coronary arteries and aorta. All testing was completed within $48 \mathrm{hrs}$ of tissue harvesting. Mechanical testing was performed using a high precision testing device adapted for testing biological specimens (Bose ElectroForce 3100, Bose Corporation, Gillingham, UK) with a load resolution of $6 \mathrm{mN}$ and a stroke resolution of $0.0015 \mathrm{~mm}$. The collagen and elastin content of the aorta, femoral and coronary arteries were also determined (see online supplementary material).

\subsection{Site specific inelasticity of arterial tree}

$3.5 \mathrm{~mm}$ diameter cylindrical radial compressive samples removed from the aorta, femoral, carotid and coronary arteries of a single pig were loaded in uniaxial cyclic compression in order to determine the inelastic strains remaining in the tissue on unloading. Samples were 
1 placed on the lower platen and the upper platen was moved to apply a small compressive pre-

2 load of $0.01 \mathrm{~N}$ to the sample at a crosshead speed of $0.001 \mathrm{~mm} / \mathrm{s}$. This ensured a consistent

3 contact between the platen and the top of the sample. The sample thickness was then taken as

4 the distance between the platens at this pre-load. The thickness of the samples tested was

5 measured as $1.39 \pm 0.089,0.597 \pm 0.036,0.676 \pm 0.079,0.581 \pm 0.099$ for aorta, carotid, femoral

6 and coronary samples respectively. Samples were loaded cyclically at a strain-rate of 0.005

$7 \mathrm{~s}^{-1}$ between $0 \%$ strain and a peak compressive strain starting at $10 \%$ and increasing

8 incrementally every 5 loading-unloading cycles by $10 \%$ up to a maximum of $60 \%$ similar to

9 previous studies (Maher et al., 2011). Testing occurred inside a water bath filled with $0.9 \%$

10 saline solution in order to maintain sample hydration during testing (Fig. 1a). 6 samples from

11 each artery were tested.

The hypothetical elastic response of the sample, i.e. the behaviour of the tissue if loaded in a monotonic uniaxial test, is estimated from the peak stress-strain points of each loading cycle which is termed the load envelope (Maher et al., 2011). The stresses in this study were expressed as the Cauchy stress $\sigma$,

$$
\sigma=\frac{F}{A_{0}} \lambda
$$

where $F$ is the magnitude of the compressive force, $A_{0}$ is the original cross-sectional area of the sample and $\lambda$ is the stretch ratio. The residual inelastic strains were determined from the strain level at which the $2^{\text {nd }}$ loading cycle from each set of 5 exceeded $0 \mathrm{MPa}$. Therefore if at a stretch of 1 the stress is $0 \mathrm{MPa}$ no inelastic deformation has occurred. 
1 the area under the stress-stretch curve between the $1^{\text {st }}$ and $2^{\text {nd }}$ loading cycle for a given peak

2 load, i.e.

3

$$
\text { Area of Stress Softening }=\left(A_{1}-A_{2}\right) \quad(\text { Eqn. 2) }
$$

where $A_{1}$ is the area under the stress-stretch curve during the first loading cycle and $A_{2}$ is the area under the stress-strain curve during the second loading cycle. The \% stress softening was defined as the percentage change in the area under the stress-stretch curve between the $1^{\text {st }}$ and $2^{\text {nd }}$ loading cycle for a given peak load, i.e.

$$
\% \text { Stress Softening }=100 *\left(A_{1}-A_{2}\right) / A_{1}
$$

Two way analysis of variance (ANOVA) was used to determine statistical significance of the data, which was set at $\mathrm{P}<0.05$. Minitab software version 15.1 (Minitab Inc, PA) was used for statistical analysis.

\subsection{Anisotropic inelastic behaviour of arterial tissue}

Due to their larger diameter, aorta and carotid arteries were tested in circumferential and longitudinal tension in addition to radial compression. These arteries were harvested from 2 pigs and 6 circumferential and longitudinal strips, approximately $2 \mathrm{~mm}$ wide and $10 \mathrm{~mm}$ long for the carotid and $3 \mathrm{~mm}$ wide and $17 \mathrm{~mm}$ long for the aorta, were excised. A similar loading profile as described for the compression testing was used for tensile testing. Strain was measured visually using a computer based video extensometer to measure changes in the distance between a grid of marks on a sample (Fig. 1b) from the initial length determined after applying an initial pre-load of $0.01 \mathrm{~N}$ (Maher et al., 2009). The displacement rate used during testing was $0.065 \mathrm{~mm} / \mathrm{s}$ and $0.035 \mathrm{~mm} / \mathrm{s}$ for the aorta and carotid tensile specimens respectively. (This results in a strain-rate of between $0.0038-0.0093 \mathrm{~s}^{-1}$ and $0.0042-0.0081$ 
$1 \mathrm{~s}^{-1}$ for the aorta and the carotid samples respectively). This rate was chosen so that the strain-

2 rate was similar in magnitude to that of the compressive testing for comparative purposes.

3 Samples were lightly sprayed regularly with biological saline solution. The loading and

4 unloading behaviour of the arteries were compared in all three directions (circumferential

5 tensile, longitudinal tensile and radial compressive) and a two way ANOVA was used to 6 determine statistical differences.

\section{3. Results}

9 Stress softening and inelastic deformations were observed on unloading in tension and compression, see Fig. 2. The typical pre-conditioning effect whereby a consistent stress-strain response occurs after repeated loading cycles is observed. This is achieved after 3-4 cycles for all artery types; however the majority of the softening occurs during the initial loadingunloading cycle for a given applied strain. An overall significant difference in the inelastic deformations on unloading from different magnitudes of compressive strains was found between all artery types $(\mathrm{p}<0.05)$, see Fig. 3. The largest inelastic strains were observed for the coronary artery while the aorta exhibited the lowest inelastic strains. A similar trend was also observed for the \% stress softening, where it tended to be greatest for the coronary artery and lowest for the aorta; although significant differences in the \% stress softening were found only for low values of applied strain $(\mathrm{P}<0.05)$, see Fig. 3 (statistical significance indicated by letters above data on figure). In contrast the area of stress softening was generally significantly lower in the coronary artery at higher values of applied strain, see Fig. 3, with no significant differences observed between the femoral artery and aorta. The coronary artery had the highest collagen to elastin ratio of those tested while the aorta has the smallest $(\mathrm{P}<0.05)$, see Fig. 4. 
2 Fig. 5. A similar stress-strain response is observed for both longitudinal tension and radial compression in both arteries, with the radial compressive behaviour tending to be less stiff. A

4

comparison between the load envelopes of the two arteries indicates that the carotid artery is stiffer in circumferential tension than the aorta. The carotid also tends to be less stiff in radial compression than the aorta while no difference between the longitudinal tensile behaviour of either artery is apparent. The largest inelastic deformations are observed in radial compressive direction and the lowest in circumferential tensile direction (Fig. 6). A significant difference $(\mathrm{P}<0.05)$ was found in the inelastic deformations between samples loaded in the three directions for both arteries at large strains (Fig. 6), however for lower applied strains the residual strains in the tissue on unloading are not significantly different in the longitudinal or radial directions. This is particularly evident for the aorta where the inelastic strain magnitudes were almost identical for radial compression and longitudinal tensile samples on unloading from $20 \%$ strain. For the carotid artery no significant difference in residual strain is observed between the circumferential and longitudinal directions on unloading from $20 \%$ strain, with higher residual strains observed in the longitudinal direction on unloading from higher magnitudes of applied strain $(\mathrm{P}<0.05)$. The ratios of the inelastic deformations (i.e. the ratios of inelastic deformation in the circumferential direction to those in either the longitudinal and radial directions) in each loading direction were found to be similar in both carotid and aortic tissue for large applied strains. On unloading from a $50 \%$ applied strain the ratio of inelastic deformation in the radial direction to the circumferential direction is approximately 2 (1.9 and 2.1 for the carotid and aorta respectively), while the ratio of longitudinal deformation to circumferential is about 1.4 (1.378 and 1.371 for the carotid and aorta respectively). An approximately linear relationship between the inelastic 
1 strain measured and the peak strain applied is observed for all arteries in all directions, see

$2 \quad$ Figs. 3 and 6.

3

4

\section{4. Discussion}

8 The aim of this study was to characterise the magnitude of inelastic deformations due to 9 loading throughout the arterial tree and to investigate the anisotropic inelastic behaviour of

No significant differences were found in the $\%$ stress softening observed due to loading in the three directions, see Fig. 7. However a large standard deviation was observed and stress softening tended to be greatest in the longitudinal direction. arterial tissue. Similar to the findings of Horny et al (2010), we observed stress-softening and residual strains with the majority of the stress-softening occurring in the first cycle of loading. The greatest inelastic strains were observed in coronary tissue, with the lowest in aortic tissue. The same trend was observed for the \% stress softening during radial compressive testing. Both aortic and carotid tissue demonstrated anisotropic inelastic behaviour where the highest inelastic strains were observed in the radial direction and the lowest in circumferential direction. The approximately linear relationship between inelastic deformations and applied stretches observed here has also been reported previously for atherosclerotic plaques (Maher et al., 2011). At higher peak strains no significant differences were observed in the $\%$ stress softening for the four artery types.

It is expected that damage in the tissue will increase for increasing applied peak strain. While the $\%$ stress softening during radial compression curves do not indicate any increase in damage, the magnitude of the change in area between 1st and 2nd loading curves (' $A_{1}-A_{2}$ ' - Eqn. 2) does increase with strain (Fig. 3). This indicates that although the \% 
1 stress softening metric does not increase with increases in applied strain (although there was a

2 non-significant trend towards a decrease in \% stress softening with increasing strain for the coronary artery), damage is increasing in the tissue but not at a greater rate at which the stress (and thus the internal energy) is increasing. Given that both the stress-strain response when

5 loading the tissue (and therefore the area $A_{1}$ ) and the change in area due to stress-softening $6 \quad\left(A_{1}-A_{2}\right)$ are related to the strain applied to the tissue and the tissue composition, it is perhaps unsurprising that the $\%$ stress softening (i.e. the ratio $\left.\left(A_{1}-A_{2}\right) / A_{1}\right)$ does not change with applied strain. The \% stress softening was higher in the coronary artery at lower levels of applied strain, which was due to the fact that the coronary artery was less stiff in radial compression (and hence $A_{1}$ is lower), rather than the area of stress softening being higher, which in fact is generally lower for coronary arteries.

Larger inelastic strains were observed in more muscular arteries where the ratio of collagen to elastin in the artery wall is highest, suggesting that the higher proportion of elastin in the media of elastic arteries is responsible for the greater elastic recovery on unloading. It has been demonstrated that elastin behaves as a perfectly elastic material up to stretches of 1.6 (Fung and Sobin, 1981). Furthermore, inelastic deformations were generally highest when the tissue is loaded in radial compression and lowest when loaded in the circumferential tensile direction. This suggests that the relative quantities and orientation of collagen, elastin and smooth muscle may all play a role in determining the magnitudes of inelastic deformations. The highest collagen to elastin ratio was observed in the coronary artery and the lowest in the aorta, in agreement with previous studies for aged canine arteries (Fischer and Llaurado, 1966). We did not determine the biochemical composition of the carotid artery. One can assume that the collagen to elastin ratio of the unanalysed carotid artery falls between that of the aorta and coronary arteries as seen in canine arteries (Cox, 1978; Fischer and Llaurado, 1966). Previous studies have shown that the collagen to elastin ratio is not 
1 significantly different in the carotid and femoral arteries (Sindram et al., 2011), although it

2 should be noted that the elastin and collagen content varies over the length of the porcine

3 carotid (Garcia et al., 2011).

During tensile testing, the near circumferentially orientated collagen fibers and anisotropic elastin network most likely both contribute to the smaller inelastic strains observed in the circumferential direction in both aorta and carotid tissue. It is speculated that more of the damage occurs in the non-fibrous component of the arterial tissue than the collagen fibers. If this is the case, the anisotropy of the inelastic response in tension can potentially be explained as follows. During testing in the circumferential direction greater recoverable energy is stored in the collagen fibers compared to when loaded in other directions due to the preferred fiber orientation. These fibers are most likely crimped in their initial configuration so can experience larger levels of tissue strain without damage. Therefore the tissue recovers more in the circumferential direction on unloading.

There are a number of limitations associated with the current study. The tissue was tested at room temperature rather than at $37{ }^{\circ} \mathrm{C}$, although it is unclear if this will affect the tissue properties (Guinea et al., 2005; Kang et al., 1995; Vilks et al., 1975). In this study we assume that the peak stress-strain points of each strain level can be used to estimate the monotonic elastic loading behaviour of the tissue (the load envelope). Using the load envelopes as an estimate implies that the carotid artery will reach a stress of $0.2 \mathrm{MPa}$ at a stretch of between 1.2 and 1.4 in the circumferential direction and 1.6 and 1.8 for the longitudinal direction, which correlates well with other studies (Garcia et al., 2011). The carotid and aorta were stiffer in the circumferential direction than the longitudinal which has been seen previously for both the carotid artery (Garcia et al., 2011) and the aorta (Yang et al., 2011). Only compression testing of coronary and femoral arteries was undertaken due to their small diameter which made circumferential tensile tests impractical. While the dominant 
1 loading experienced by arterial tissue during expansion of angioplasty balloons and stents is

2 tensile, the inelastic deformations that occur due to radial compressive loading are

3 approximately twice that due to circumferential loading for large applied peak strains.

4

The use of healthy porcine tissue is a limitation of this study. While the structure and mechanical properties may differ between porcine and human arteries, the components of the arterial walls that effect arterial mechanics (elastin, collagen, smooth muscle and ground matrix) are similar. It has been observed that human and porcine thoracic aortic media have a similar lamellar structure and the arterial wall tension per lamellar unit is relatively constant between species (Wolinsky and Glagov, 1967). This indicates that a comparison of inelasticity among the different vascular beds in the swine may provide valuable insight into the mechanics of human arteries. Another potential limitation is that the method used to determine differences in collagen makes a number of assumptions which may impact the absolute values determined, but not the relative differences in collagen content. Similar assumptions have been made in the literature (Sindram et al., 2011).

No analysis of the effects of strain-rate on the results was carried out (although preliminary tests were undertaken to rule out viscoelastic or poroelastic effects - see online supplementary material). Based on relevant literature (Lee and Haut, 1992; Tanaka and Fung, 1974; Topoleski et al., 1997), this was judged to be suitably slow strain-rate for testing to be considered quasi-static while allowing all testing to be completed within $48 \mathrm{hrs}$ of harvesting. While other authors have found that strain-rate effects the stress-strain and failure behaviour of arterial tissue in tension (Collins and Hu, 1972; Mohan and Melvin, 1982), these studies commonly compare strain-rates differing by a number of orders of magnitude and the strainrates that are considered to be quasi-static in these studies are often of a similar or greater magnitude than used here. The ultimate tensile stress and stretch to strain-rate has also been 
1 shown to be relatively insensitive to strain-rate over a wide range (Lee and Haut, 1992;

2 Monson et al., 2003).

3

4

5

6

7

In conclusion, this study characterised the inelastic response of common carotid, coronary, aorta and femoral arteries due to compressive loading and found that the largest inelastic strains occur in the more muscular arteries. It was observed that lower inelastic strains occur in the circumferential direction and we speculate that this may be a result of the matrix in the media becoming more damaged due to loading than the collagen fibers, allowing greater recovery when stretched in the circumferential direction. A constitutive model that separates the response of the matrix and collagen fibers and the damage that occurs in each may provide further insight into the tissues inelastic response, and may prove useful in finite element simulations of stent-artery interactions (Auricchio et al., 2011; Early and Kelly, 2011; Early and Kelly, 2010; Early et al., 2009; Mortier et al., 2010; Pericevic et al., 2009).

\section{Acknowledgements}

This material is based on works supported by the Science Foundation Ireland under Grant No. 07/RFP/ENMF660 
References

2 Auricchio, F., Conti, M., De Beule, M., De Santis, G., Verhegghe, B., 2011, Carotid artery

3

4

5

6

7 stenting simulation: From patient-specific images to finite element analysis. Medical Engineering \& Physics 33, 281-289.

Balzani, D., Brinkhues, S., Holzapfel, G.A., 2011, Constitutive Framework for the Modeling of Damage in Collagenous Soft Tissues with Application to Arterial Walls. Comp. Methods Appl. Mech. Engrg.

Collins, R., Hu, W.C., 1972, Dynamic deformation experiments on aortic tissue. J Biomech $5,333-337$.

Cox, R.H., 1978, Passive mechanics and connective tissue composition of canine arteries. Am J Physiol 234, H533-541.

Dixon, S.A., Heikes, R.G., Vito, R.P., 2003, Constitutive modeling of porcine coronary arteries using designed experiments. J Biomech Eng 125, 274-279.

Early, M., Kelly, D., 2011, The consequences of the mechanical environment of peripheral arteries for nitinol stenting. Medical and Biological Engineering and Computing, 110.

Early, M., Kelly, D.J., 2010, The role of vessel geometry and material properties on the mechanics of stenting in the coronary and peripheral arteries. Proceedings of the Institution of Mechanical Engineers. Part H 224, 465-476.

Early, M., Lally, C., Prendergast, P.J., Kelly, D.J., 2009, Stresses in peripheral arteries following stent placement: a finite element analysis Computer Methods in Biomechanics and Biomedical Engineering 12, 25-33.

Fischer, G.M., Llaurado, J.G., 1966, Collagen and elastin content in canine arteries selected from functionally different vascular beds. Circ Res 19, 394-399. 
1 Fung, Y.C., Sobin, S.S., 1981, The Retained Elasticity of Elastin Under Fixation Agents. Journal of Biomechanical Engineering 103, 121-122.

Garcia, A., Pena, E., Laborda, A., Lostale, F., De Gregorio, M.A., Doblare, M., Martinez, M.A., 2011, Experimental study and constitutive modelling of the passive mechanical properties of the porcine carotid artery and its relation to histological analysis: Implications in animal cardiovascular device trials. Med Eng Phys 33, 665-676.

Guinea, G.V., Atienza, J.M., Elices, M., Aragoncillo, P., Hayashi, K., 2005, Thermomechanical behavior of human carotid arteries in the passive state. Am J Physiol Heart Circ Physiol 288, H2940-2945.

Holzapfel, G.A., 2006, Determination of material models for arterial walls from uniaxial extension tests and histological structure. J Theor Biol 238, 290-302.

Holzapfel, G.A., Sommer, G., Gasser, C.T., Regitnig, P., 2005, Determination of layerspecific mechanical properties of human coronary arteries with nonatherosclerotic intimal thickening and related constitutive modeling. Am J Physiol Heart Circ Physiol 289, H2048-2058.

Holzapfel, G.A., Sommer, G., Regitnig, P., 2004, Anisotropic Mechanical Properties of Tissue Components in Human Atherosclerotic Plaques. Journal of Biomechanical Engineering 126, 657-665.

Horny, L., Gultová, E., Chlup, H., Sedlácek, R., Kronek, J., Vesely, J., Zitny, R., 2010, Mullins Effect in Aorta and Limiting Extensibility Evolution. Bulletin of Applied Mechanics 5, 1-5.

Kang, T., Resar, J., Humphrey, J.D., 1995, Heat-induced changes in the mechanical behavior of passive coronary arteries. J Biomech Eng 117, 86-93.

Lally, C., Reid, A.J., Prendergast, P.J., 2004, Elastic behavior of porcine coronary artery tissue under uniaxial and equibiaxial tension. Ann Biomed Eng 32, 1355-1364. 
1 Lee, M.C., Haut, R.C., 1992, Strain rate effects on tensile failure properties of the common carotid artery and jugular veins of ferrets. J Biomech 25, 925-927.

Maher, E., Creane, A., Sultan, S., Hynes, N., Lally, C., Kelly, D.J., 2009, Tensile and compressive properties of fresh human carotid atherosclerotic plaques. J Biomech 42, 2760-2767.

Maher, E., Creane, A., Sultan, S., Hynes, N., Lally, C., Kelly, D.J., 2011, Inelasticity of Human Carotid Atherosclerotic Plaque. Ann Biomed Eng.

Martini, F.H., 2006, Fundamentals of Anatomy and Physiology, 7th Edition. BenjaminCummings.

Mohan, D., Melvin, J.W., 1982, Failure properties of passive human aortic tissue. I--uniaxial tension tests. J Biomech 15, 887-902.

Monson, K.L., Goldsmith, W., Barbaro, N.M., Manley, G.T., 2003, Axial mechanical properties of fresh human cerebral blood vessels. J Biomech Eng 125, 288-294.

Mortier, P., Holzapfel, G.A., De Beule, M., Van Loo, D., Taeymans, Y., Segers, P., Verdonck, P., Verhegghe, B., 2010, A novel simulation strategy for stent insertion and deployment in curved coronary bifurcations: comparison of three drug-eluting stents. Annals of Biomedical Engineering 38, 88-99.

Pandit, A., Lu, X., Wang, C., Kassab, G.S., 2005, Biaxial elastic material properties of porcine coronary media and adventitia. Am J Physiol Heart Circ Physiol 288, H25812587.

Patel, D.J., Janicki, J.S., 1970, Static elastic properties of the left coronary circumflex artery and the common carotid artery in dogs. Circ Res 27, 149-158.

Pena, E., 2011, Prediction of the softening and damage effects with permanent set in fibrous biological materials. J. Mech. Phys. Solids 59, 1808 - 1822. 
1 Pericevic, I., Lally, C., Toner, D., Kelly, D.J., 2009, The influence of plaque composition on underlying arterial wall stress during stent expansion: The case for lesion-specific stents. Medical Engineering \& Physics 31, 428-433.

Roach, M.R., Burton, A.C., 1957, The reason for the shape of the distensibility curves of arteries. Can J Biochem Physiol 35, 681-690.

Salvucci, F.P., Bia, D., Armentano, R.L., Barra, J.G., Craiem, D., Zocalo, Y., Fernandez, J.D., Baguear, F., Atienza, J.M., Rojo, F.J., Guinea, G.V., 2009, Association between mechanics and structure in arteries and veins: theoretical approach to vascular graft confection. Conf Proc IEEE Eng Med Biol Soc 2009, 4258-4261.

Schulze-Bauer, C.A., Morth, C., Holzapfel, G.A., 2003, Passive biaxial mechanical response of aged human iliac arteries. J Biomech Eng 125, 395-406.

Silver, F.H., Snowhill, P.B., Foran, D.J., 2003, Mechanical behavior of vessel wall: a comparative study of aorta, vena cava, and carotid artery. Ann Biomed Eng 31, 793 803.

Sindram, D., Martin, K., Meadows, J.P., Prabhu, A.S., Heath, J.J., McKillop, I.H., Iannitti, D.A., 2011, Collagen-elastin ratio predicts burst pressure of arterial seals created using a bipolar vessel sealing device in a porcine model. Surg Endosc 25, 2604-2612.

Sommer, G., Regitnig, P., Koltringer, L., Holzapfel, G.A., 2010, Biaxial mechanical properties of intact and layer-dissected human carotid arteries at physiological and supraphysiological loadings. Am J Physiol Heart Circ Physiol 298, H898-912.

Stemper, B.D., Yoganandan, N., Pintar, F.A., 2007, Mechanics of arterial subfailure with increasing loading rate. Journal of Biomechanics 40, 1806-1812.

Tanaka, T.T., Fung, Y.C., 1974, Elastic and inelastic properties of the canine aorta and their variation along the aortic tree. J Biomech 7, 357-370. 
1 Teng, Z., Tang, D., Zheng, J., Woodard, P.K., Hoffman, A.H., 2009, An experimental study on the ultimate strength of the adventitia and media of human atherosclerotic carotid arteries in circumferential and axial directions. J Biomech 42, 2535-2539.

Topoleski, L.D., Salunke, N.V., Humphrey, J.D., Mergner, W.J., 1997, Composition- and history-dependent radial compressive behavior of human atherosclerotic plaque. $\mathrm{J}$ Biomed Mater Res 35, 117-127.

Vilks, Y.K., Saulgozis, Y.Z., Yanson, K.A., 1975, Effect of temperature on changes of tensile stress at constant elongation in certain human soft tissues. Mechanics of Composite Materials 11, 780-784.

Walraevens, J., Willaert, B., De Win, G., Ranftl, A., De Schutter, J., Sloten, J.V., 2008, Correlation between compression, tensile and tearing tests on healthy and calcified aortic tissues. Med Eng Phys 30, 1098-1104.

Wolinsky, H., Glagov, S., 1967, A lamellar unit of aortic medial structure and function in mammals. Circ Res 20, 99-111.

Yang, T., Chui, C.K., Yu, R.Q., Qin, J., Chang, S.K., 2011, Quasi-linear viscoelastic modeling of arterial wall for surgical simulation. Int J Comput Assist Radiol Surg.

Zou, Y., Zhang, Y., 2009, An experimental and theoretical study on the anisotropy of elastin network. Ann Biomed Eng 37, 1572-1583. 


\section{$1 \quad$ Figure Legends}

2 Figure 1: (A) Schematic of the test rig for uniaxial compressive testing. The saline bath and 3 stainless steel compressive platens are screw based and detachable. For tensile testing these

4 are removed and replaced with tensile grips. (B) Image of test specimen during tensile test 5 using a video-extensometer. The video-extensometer is used to track dots on the surface of 6 the specimen to determine strain.

8 Figure 2: Typical stress stretch response of aortic tissue due to (a) tensile and (b) compressive 9 loading. The magnitude of the compressive stress is used for ease of comparison. Inset shows 10 first loading phase of each strain level only. (c) and (d) show the same samples tested as (a) and (b) respectively with the data for the $5^{\text {th }}$ unloading cycle superimposed with red triangles to highlight the unloading behaviour of the material. The unloading stress-strain response of the previous cycles is nearly identical to the $5^{\text {th }}$ cycle highlighted.

Figure 3: Magnitude of inelastic residual strains, \% stress softening and the area of stress softening (as defined in the Materials and Methods section) on unloading from various peak nominal strains in arterial samples due to compressive loading of samples from different locations in the arterial tree. $c, d$ and $e$ indicate statistical differences $(\mathrm{P}<0.05)$ between coronary samples and either the femoral, carotid or aorta samples respectively; $f$ and $g$ statistical differences $(\mathrm{P}<0.05)$ between femoral and either carotid or aorta respectively; $h$ indicates statistical differences $(\mathrm{P}<0.05)$ between carotid and aorta on unloading from a given peak load. 
1 Figure 4: Collagen to elastin ratio (C:E) (mean \pm standard deviation) of three different artery

2 types. Statistical difference $(\mathrm{P}<0.05)$ is indicated with an asterisk $(*)$.

3

4 Figure 5: Hypothetical circumferential and longitudinal tensile and radial compressive elastic

5 loading response, estimated as the load envelope, for aortic and carotid samples. The 6 magnitude of compressive stresses is used to aid comparison.

7

8 Figure 6: Magnitude of inelastic residual strains on unloading from various peak nominal 9 strains applied uniaxially in three loading directions to (a) aortic and (b) carotid tissue 10 samples and the respective mean value for both arteries (c), (d). e, f and g indicate statistical 11 differences $(\mathrm{P}<0.05)$ between values in the radial and longitudinal, radial and circumferential 12 and longitudinal and circumferential directions respectively.

14 Figure 7: \% stress softening on unloading from various peak nominal strains applied 15 uniaxially in three loading directions to aortic and carotid tissue samples and the respective mean value for both arteries. 
Click here to download high resolution image
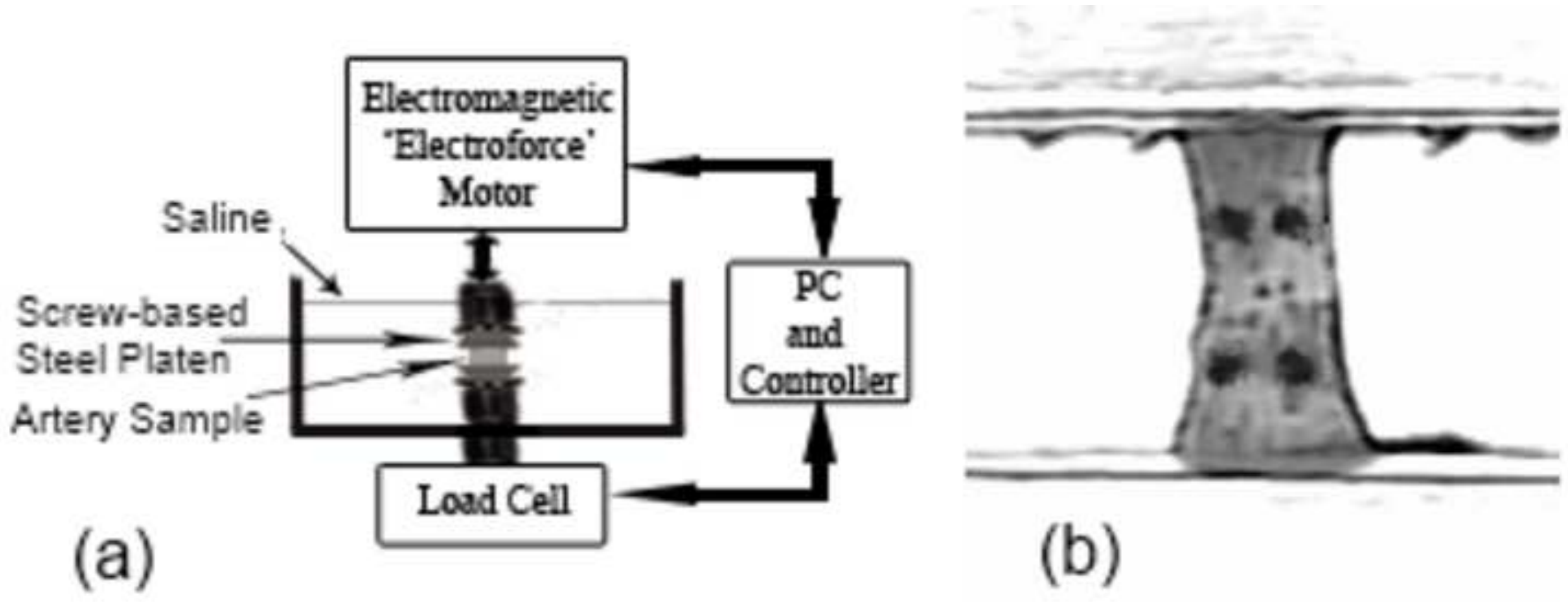

\section{(b)}



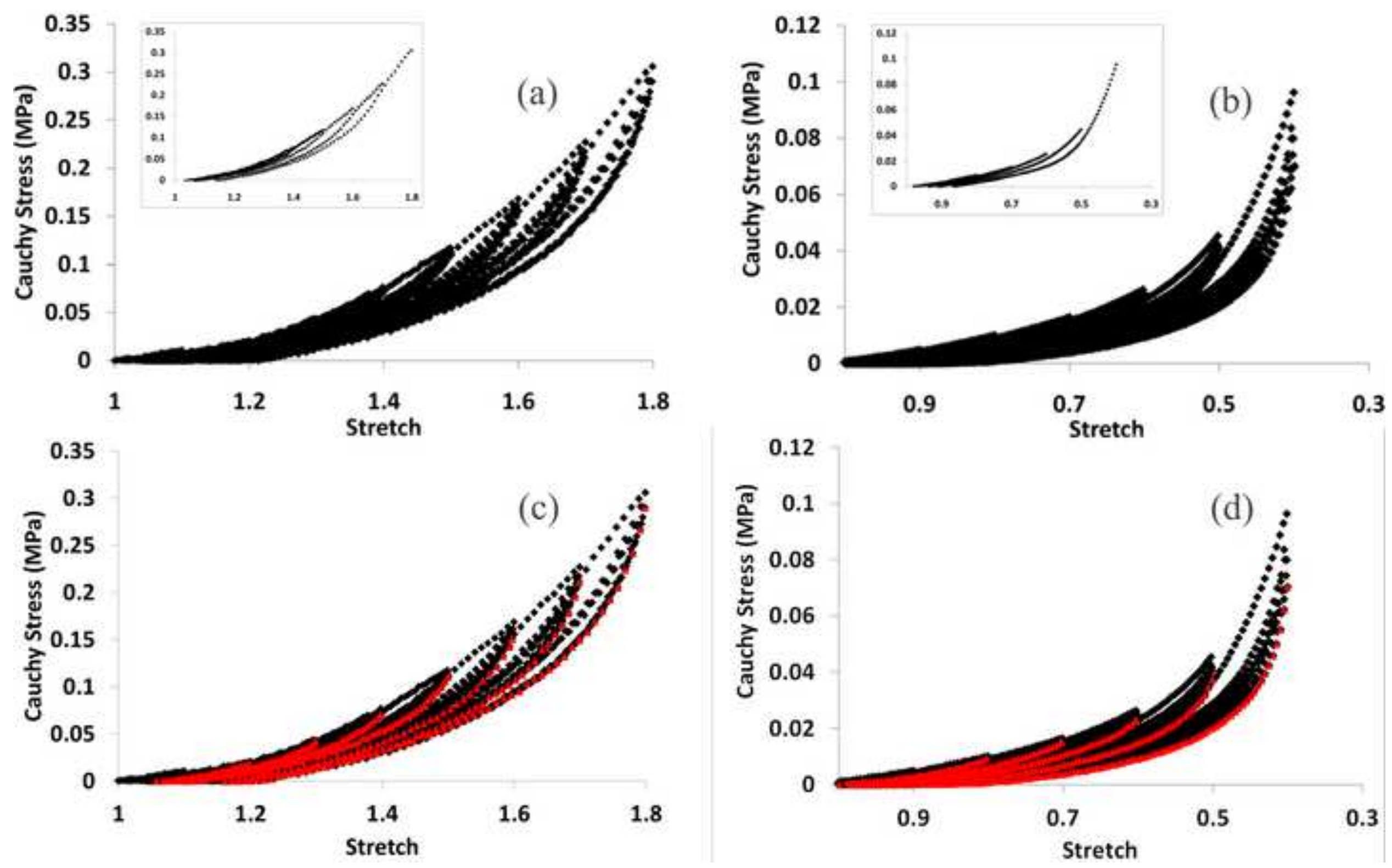
Click here to download high resolution image
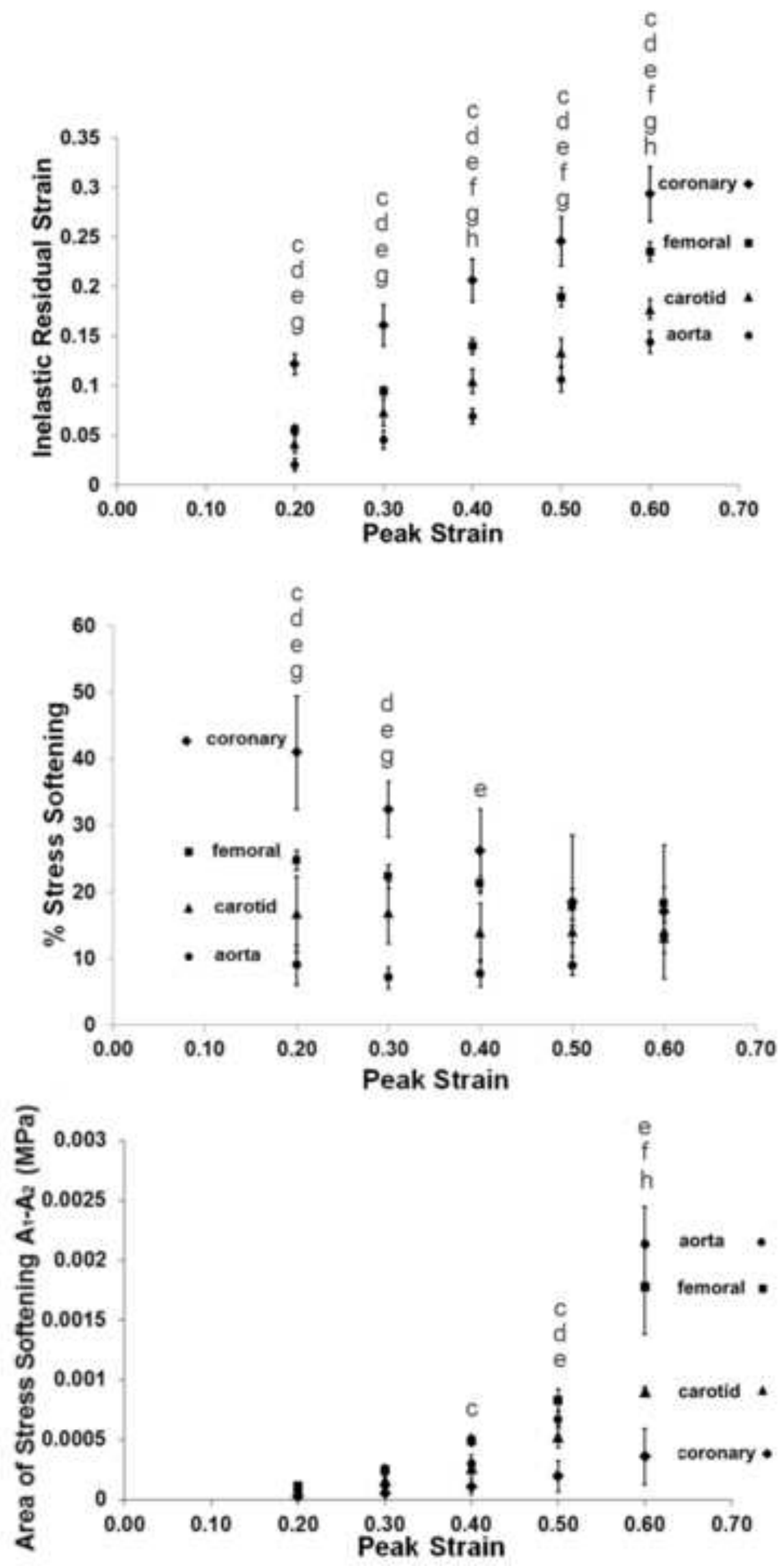


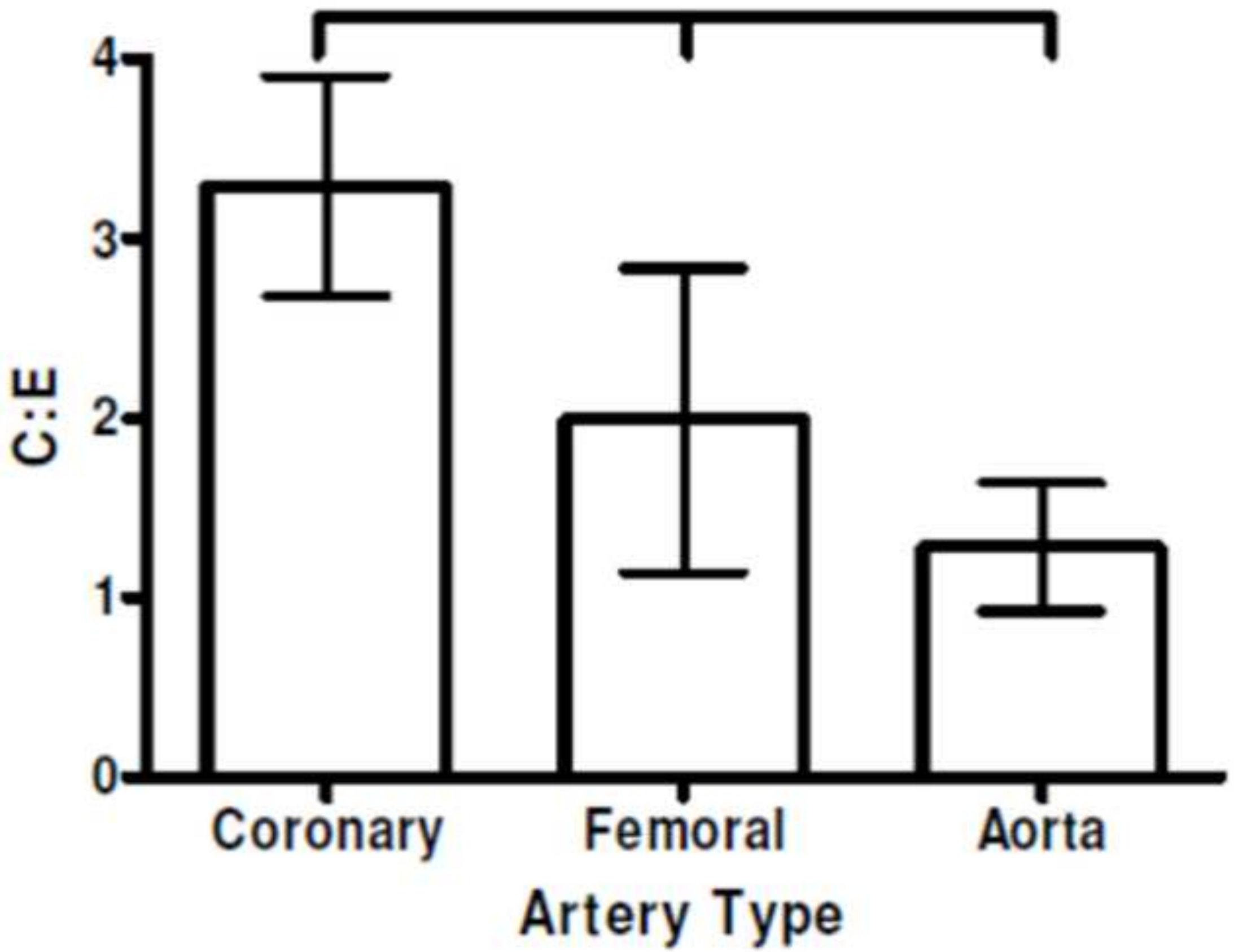



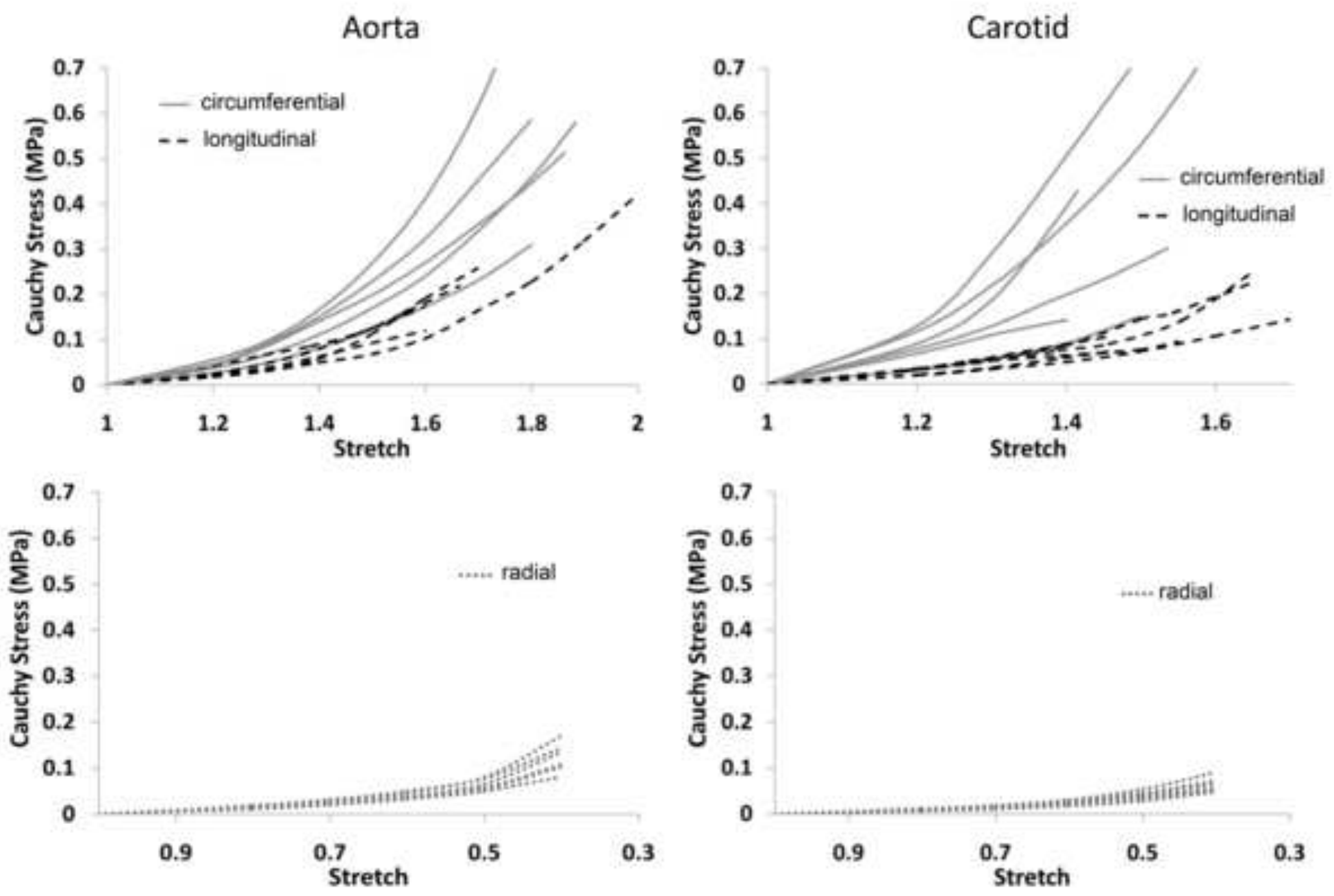

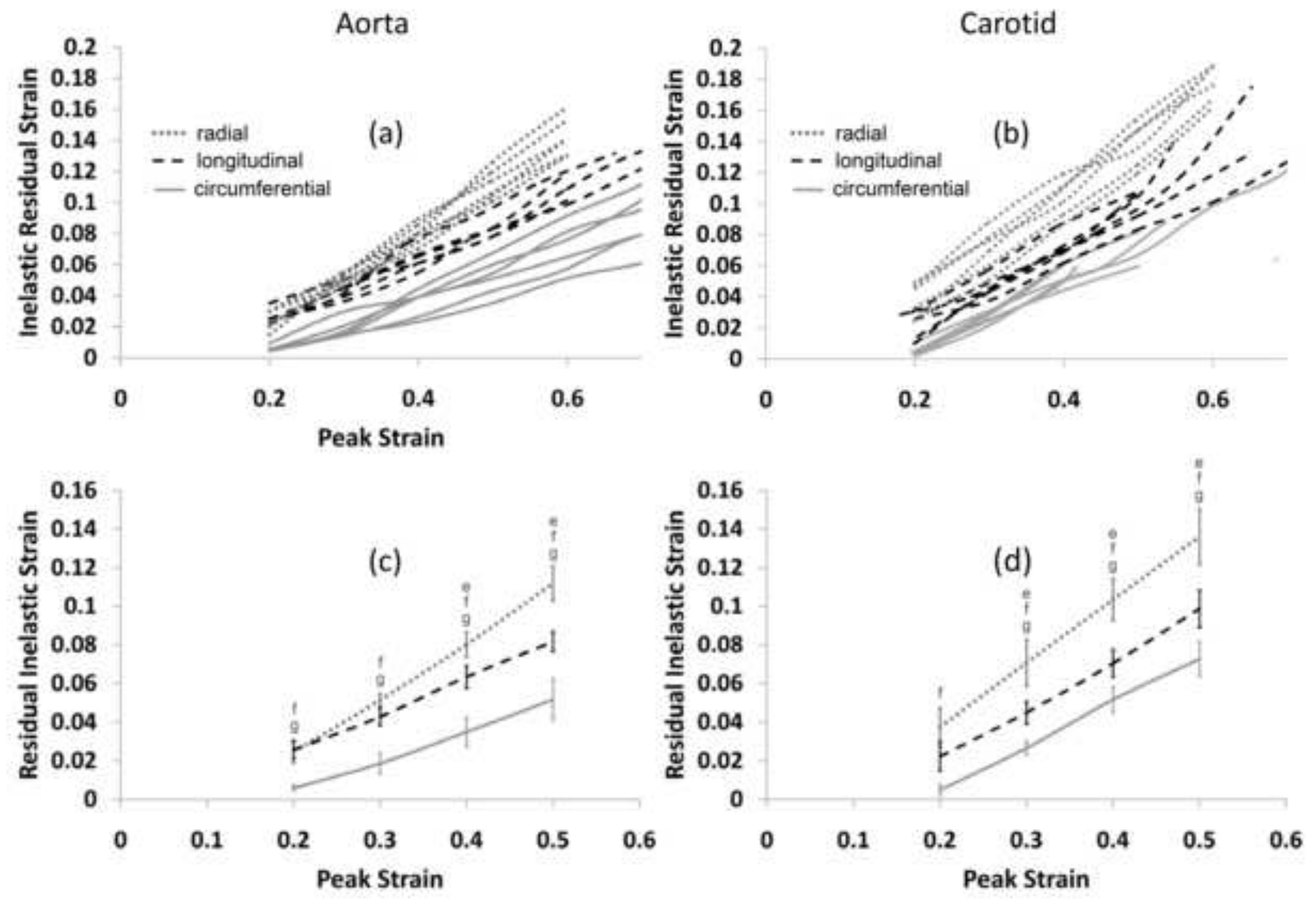
25

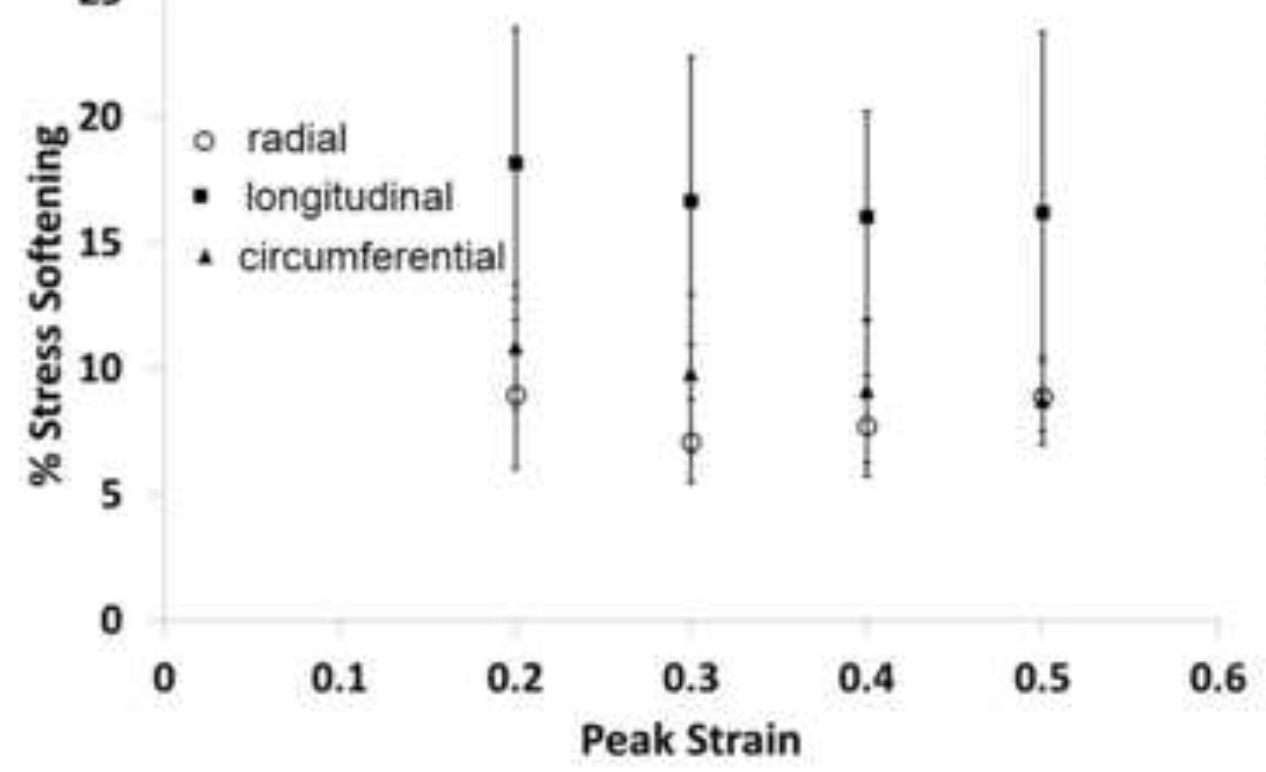

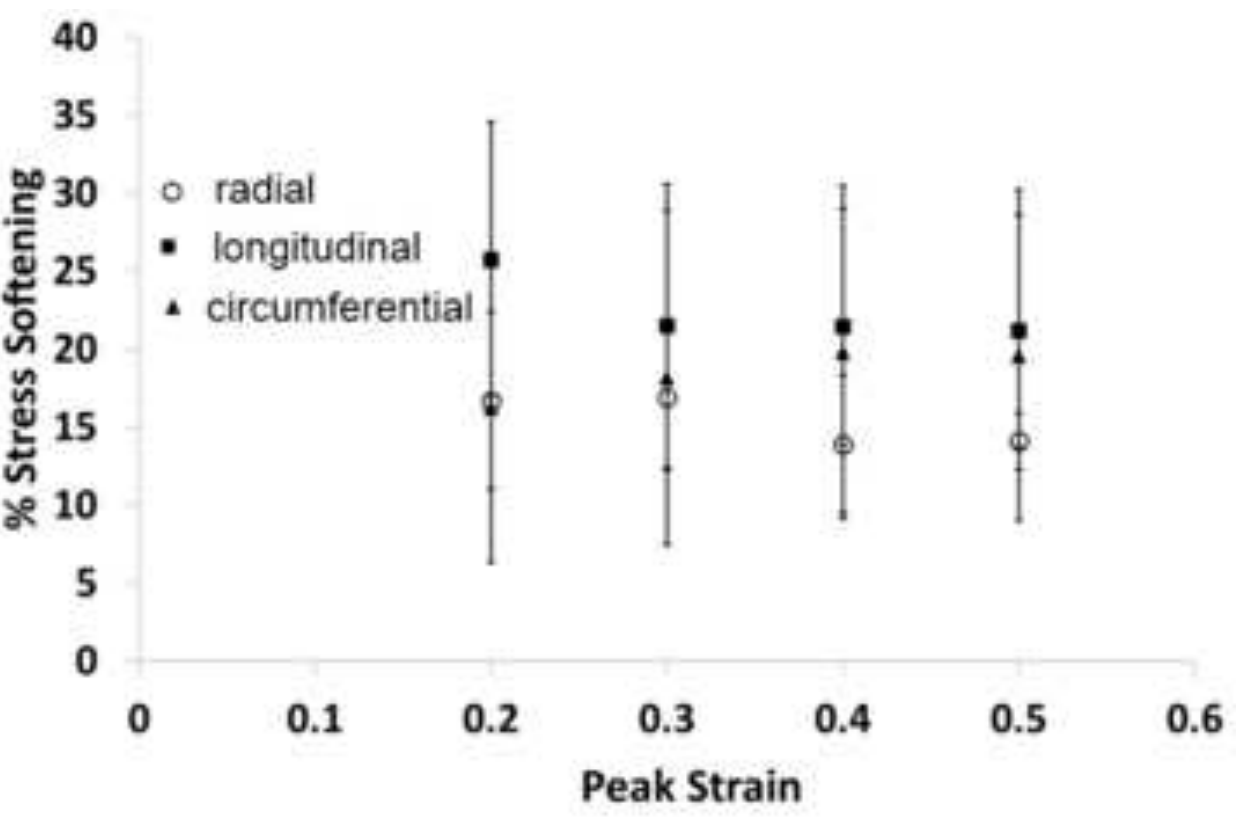


Supplementary Material
Click here to download Supplementary Material: Supplementary Material.docx

Supplementary Material
Click here to download Supplementary Material: Supplementary Material.docx

\begin{abstract}
click here to download Supplementary Material: Supplementary Materialdocx
\end{abstract}

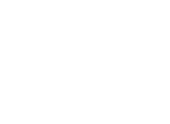

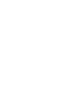

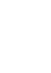

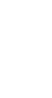

.

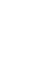

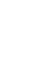

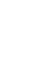

更 更 更 更

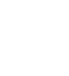
更 更 更 更 更 更 更 更 更 更 更 更 更 更 


\section{Conflict of interest statement}

DJK is a shareholder in Synergy Flow Ltd and a co-inventor of patents licensed to Synergy Flow Ltd. 